\title{
Optimal Machining Parameters for Achieving the Desired Surface Roughness in Turning of Steel
}

\author{
LB Abhang* and M Hameedullah \\ Department of Mechanical Engineering, Aligarh Muslim University, Aligarh, India
}

Received 26 July 2010; accepted 1 January 2011

\begin{abstract}
Due to the widespread use of highly automated machine tools in the metal cutting industry, manufacturing requires highly reliable models and methods for the prediction of output performance in the machining process. The prediction of optimal manufacturing conditions for good surface finish and dimensional accuracy plays a very important role in process planning. In the steel turning process the tool geometry and cutting conditions determine the time and cost of production which ultimately affect the quality of the final product. In the present work, experimental investigations have been conducted to determine the effect of the tool geometry (effective tool nose radius) and metal cutting conditions (cutting speed, feed rate and depth of cut) on surface finish during the turning of EN-31 steel. First and second order mathematical models are developed in terms of machining parameters by using the response surface methodology on the basis of the experimental results. The surface roughness prediction model has been optimized to obtain the surface roughness values by using LINGO solver programs. LINGO is a mathematical modeling language which is used in linear and nonlinear optimization to formulate large problems concisely, solve them, and analyze the solution in engineering sciences, operation research etc. The LINGO solver program is global optimization software. It gives minimum values of surface roughness and their respective optimal conditions.
\end{abstract}

Keywords: Metal cutting, Response surface methodology, Surface roughness, Optimization

$$
\begin{aligned}
& \text { عوامل التشغيل المثلى للوصول إلى المششونة المنشودة للأسطح في خراطة الصلب } \\
& \text { ل ل ال ب. ابهنج" وم. حميد الله }
\end{aligned}
$$

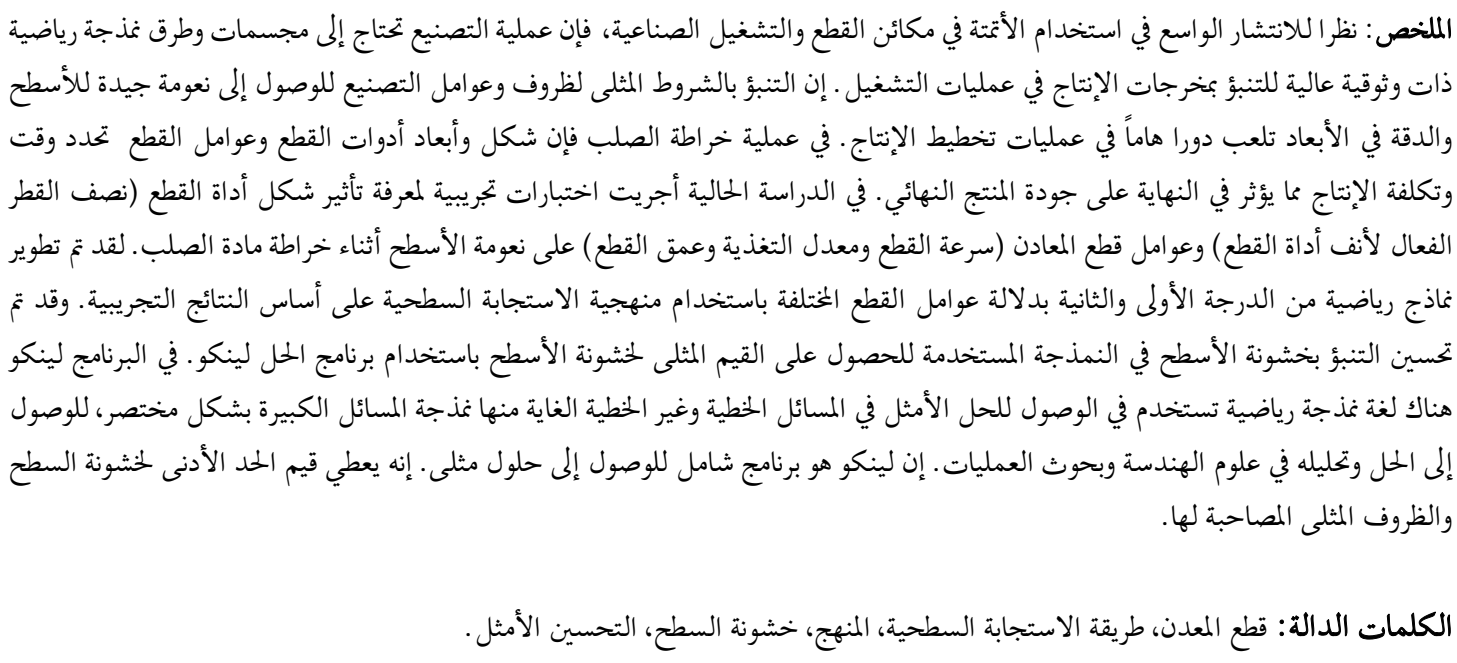

\section{Introduction}

Optimization of parameters in machining is a non linear model with constraints, so it is difficult to conducted this optimization using conventional approaches. As an alterna-tive, non-conventional approaches

$\overline{\text { *Correponding author's e-mail: abhanglb@yahoo.co.in }}$ have become useful approaches to solve machining parameter optimization problems. The LINGO solver program is global optimization software; it gives minimum values of surface roughness and their respective optimal conditions. In many real machining applica- 
tions, three conflicting objectives are often considered. These are the maximum production rate, minimum operational cost, and quality of machining. Therefore, three cutting parameters and tool geometries need to be determined in a turning operation: cutting velocity feed rate, depth of cut, and tool nose radius. The purpose of the turning operation is to produce low surface roughness. Proper selection of cutting parameters and tools can produce longer tool life and lower surface roughness. Hence, the design of experiments by factorial input, with response surface methodology (R.S.M). applied to cutting parameters, was adopted to study the surface roughness (Abhang, Hameedullah 2010). Hard turning eliminates the series of operation required to produce the component and thereby reduces the metal cutting cycle time. This results in improvement of productivity (Konig et al. 1984). The proper selection of the cutting tool inserts and cutting conditions plays an important role in process planning for steel turning. This task is traditionally completed by the process planner by taking the data from the hand books and cutting tool catalogues. Since different cutting tool inserts are available with different geometries, coatings and materials, it becomes difficult for the process planner to decide the required inserts on the basis of available data (Wang et al. 2002). It is necessary that reliable mathematical models be formulated so that optimum selection of tool geometry and cutting parameters can be achieved. To date very few models have been developed for the case of EN-31 alloy steel turning incorporating tool geometry (tool nose radius) and the cutting conditions. Researchers have studied the effect of the metal cutting parameters on surface roughness, but the combined effect of tool nose radius and cutting parameters (cutting speed, feed rate, and depth of cut) has not been studied properly.

Therefore, in this paper, an effort has been made to develop the mathematical models incorporating tool geometry (tool nose radius) and cutting conditions by performing the experiments on the EN-31 alloy steel with a tungsten carbide tool and then optimizing the turning process by LINGO-solver programmer. Suresh et al. (2002) have developed a surface roughness prediction model for turning mild steel using a response surface methodology. As surface roughness prediction model has also been optimized by using genetic algorithms. Feng, Wang (2002) have developed empirical models for surface roughness prediction in finish turning. They have included work piece hardness, feed rate, and tool point angle, depth of cut, cutting speed and cutting time. Ozel, Karpat (2005) studied the predictive modeling of surface roughness and tool wear in hard turning using regression and neural networks. The cutting tool used was made of cubic boron nitride. In this study, effects of cutting edge radius, work-piece hardness, cubic-baron-nitride (CBN) context, cutting length, cutting speed and feed rate on surface roughness and tool wear were experimentally investigated. Effective rake angle was kept constant in this study. Dilbag (2007) studied the optimization of tool geometry and cutting parameters for hard turning. The cutting tool used was made of mixed ceramic inserts. In this study, effects of cutting speed, feed rate, and negative rake angle and tool nose radius on surface roughness were experimentally investigated. However, effective depth of cut has been kept constant through out the study. Yang, Tarng (1998) employed the Taguchi method to investigate the cutting characteristics of S45C steel bars using tungsten carbide tools. The optimal cutting parameters namely, cutting speed, feed rate and depth of cut for turning operations with regard to performance indexes such as tool life and surface roughness are considered. Kopac et al. (2002) investigated the optimal machining parameters for achieving good surface roughness in fine turning of cold pre-formed steel C15 E4 (ISO). Manna, Bhattacharyya (2004) took the significant cutting parameters into consideration and used multiple linear regression mathematical models relating the surface roughness height $\mathrm{Ra}$ and $\mathrm{Rt}$ to the cutting parameters for turning Al/SiC-MMC. Aslan et al. (2007) used an orthogonal array and analysis of variance to optimize cutting parameters in turning hardened AISI4140 steel with a $\mathrm{Al}_{2} \mathrm{O}_{3}$ ceramic tool coated with TiCN. The flank wear and surface roughness had been selected as investigated quality objectives and the authors tried to determine optimal values of cutting parameters, such as cutting speed, feed rate and depth of cut. Nalbant et al. (2007) used the Taguchi method to find good surface roughness in turning of AISI 1030 steel bars using TiN coated tools in terms of three cutting parameters, namely insert radius, feed rate and depth of cut.

It is evident from the above-mentioned literature that all the models studied only cutting parameters (i.e., cutting conditions) for the turning process. Additionally, the optimization of the tool geometry (considering effective tool nose radius) and the metal cutting conditions for the EN-31 alloy steel turninghave never been reported. Therefore, an effort has been made in this paper to obtain the optimum values of the tool geometry and the cutting conditions for minimizing the surface roughness by LINGO-solver software.

\section{Methodology}

In this work, experimental results were used for modeling using response surface roughness methodology (RSM). RSM is a collection of mathematical and statistical techniques that are useful for the modeling 
and analysis of problems in which response of interest is influenced by several variables and the objective is to optimize the response. RSM is practical, economical and relatively easy for use. Additionally it has been widely researched in the modeling metal cutting process (Birdie 1993, Hasegawa et al. 1976; Montgomery 1991). RSM was also successfully used for application in tool life testing (Abhang et al. 2010; Mehrban et al. 2008) surface analysis and tool wear rate in metal cutting. The experimental data was utilized to build a mathematical model (first order, second order, and an exponential model) by the regression method. This mathematical model was taken as objective function and was optimized using a LINGOsolver programmer to obtain the machining conditions for the required surface finish The following linear relationship is commonly used for representing the mathematical models in metal cutting:

$$
Y=\varnothing(v, f, d, r)+\varepsilon
$$

Where, $v, f, d$, and $r$ are the speed, feed, depth of cut and tool nose radius respectively of the metal cutting processes, and $\varepsilon$ is the error, which is normally distributed with mean $=0$ according to observed response $\mathrm{Y}$ and $\varnothing$ is the response function. The relationship between surface roughness and other independent variables is modeled as shown below:

$$
R_{a}=c v^{a} f^{b} d^{c} r^{d}
$$

Where $\mathrm{c}$ is constant, $\mathrm{b}, \mathrm{c}$, and $\mathrm{d}$ are the exponents. Equation (2) can be represented in linear mathematical from as shown:

$$
\ln R_{a}=\ln (c)+a \ln v+b \ln (f)+c \ln d+d \ln r
$$

The constants and exponents $\mathrm{a}, \mathrm{b}, \mathrm{c}$ and $\mathrm{d}$ can be obtained by the method of least squares. The firstorder linear model developed from the equation, can be represented as follows.

$$
Y_{1}=y-\varepsilon=b_{\mathrm{o}} x_{\mathrm{o}}+b_{1} x_{1}+b_{2} x_{2}+b_{3} x_{3}+b_{4} x_{4}
$$

Where, $Y_{l}$ is the estimated response based on firstorder equation on the logarithmic scale, $\mathrm{y}$ is the measured surface roughness $x_{o}=1$ (dummy variable), $x_{1}, x_{2}$, $x_{3}$ and $x_{4}$ are logarithmic transformations of cutting speed, feed rate, depth of cut, and tool nose radius, respectively. the experimental error is $\varepsilon$ and b-values are the estimates of corresponding parameters. If this model is not sufficient to represent the process, then the second-order model will be developed. The general second order model is as given below:

$$
\begin{aligned}
Y_{2} & =Y-\varepsilon=b_{o} x_{o}+b_{1} x_{1}+b_{1} x_{2}+b_{3} x_{3} \\
& +b_{4} x_{4}+b_{12} x_{1} x_{2}+b_{23} x_{2} x_{3}+b_{14} x_{1} x_{4} \\
& +b_{24} x_{2} x_{4}+b_{13} x_{4} x_{3}+b_{34} x_{3} x_{4}+b_{11} x_{1}{ }^{2} \\
& +b_{22} x_{2}{ }^{2}+b_{33} x_{3}{ }^{2}+b_{44} x_{4}{ }^{2}
\end{aligned}
$$

Where $\mathrm{Y}_{2}$ is the estimated response based on second order equation, the parameters $b_{0}, b_{1}, b_{2}, b_{3}, b_{4}$, $b_{11}, b_{12}, b_{13}$ and $b_{44}$ are to be estimated by the method of least squares.

\section{Optimization of Surface finish by the LINGO- solver Approach}

LINGO is a mathematical modeling language which is used in linear and non-linear optimization in engineering sciences, operation research, etc. The simplicity of operation and computational efficiency are the two main attractions of the LINGO solver approach. Optimization helps find the answer that yields the best result, or attains the highest profit, output, or happiness. It also has the potential to find the answer that achieves the lowest cost, minimize surface roughness, minimizes waste, or prevents discomfort. Through the LINGO solver optimization we can obtain the global optimum values (i.e., minimization or maximization characteristics).

\section{Experimental Details}

A detailed survey has been carried out to find out how metal cutting parameters, namely cutting speed, feed rate, depth of cut and tool nose radius of the single point cutting tool were selected for experimentation. The range of each parameter is set at three different levels, namely low, middle and high based on industrial practices as shown in Table 1. The factorial design with eight added centre points $\left(2^{4}+8\right)$ used in this work is a composite design. The complete design consists of 24 experiments as shown in Table 2 (all factors are in coded form). The coded number for variables used in Tables 1 and 2 are obtained from the following transformation equations as suggested by (Birdie 1993; Montgomery 1991):

$$
\begin{aligned}
& X_{1}=(\ln v-\ln 112) /(\ln 112-\ln 39) \\
& X_{2}=(\ln f-\ln 0.10) /(\ln 0.10-\ln 0.06) \\
& X_{3}=(\ln d-\ln 0.4) /(\ln 0.4-\ln 0.2) \\
& X_{4}=(\ln r-\ln 0.8) /(\ln 0.8-\ln 0.4)
\end{aligned}
$$

Where $x_{1}$ is the coded value of cutting speed $\mathrm{v}, x_{2}$ is the coded value of feed rate $\mathrm{f}, x_{3}$ is the coded value of depth of cut $d$, and $x_{4}$ is the coded value of tool nose radius $r$. 
Table 1. Process variabls and their levels

\begin{tabular}{llllll}
\hline Level & $\begin{array}{l}\mathrm{V} \\
\mathrm{m} / \mathrm{min}\end{array}$ & $\begin{array}{l}\mathrm{F} \\
\mathrm{mm} / \mathrm{rev}\end{array}$ & $\begin{array}{l}\mathrm{D} \\
\mathrm{mm}\end{array}$ & $\begin{array}{l}\mathrm{R} \\
\mathrm{mm}\end{array}$ & $\begin{array}{l}\text { Cod- } \\
\text { ing }\end{array}$ \\
\hline Low & 39 & 0.2 & 0.2 & 0.4 & - \\
Middle & 112 & 0.10 & 0.4 & 0.8 & 0 \\
High & 189 & 0.15 & 0.6 & 1.2 & + \\
\hline
\end{tabular}

Table 2. Design matrix with experimental results

\begin{tabular}{cccccc}
\hline $\begin{array}{c}\text { Sr. } \\
\text { No. }\end{array}$ & $\mathrm{X}_{1}$ & $\mathrm{X}_{2}$ & $\mathrm{X}_{3}$ & $\mathrm{X}_{4}$ & $\begin{array}{c}\text { Response } \\
\text { Ra },(\mu \mathrm{m})\end{array}$ \\
\hline 1 & -1 & -1 & -1 & -1 & 10.43 \\
2 & -1 & -1 & -1 & +1 & 10.10 \\
3 & -1 & -1 & +1 & -1 & 12.45 \\
4 & -1 & -1 & +1 & +1 & 12.23 \\
5 & -1 & +1 & -1 & -1 & 13.87 \\
6 & -1 & +1 & -1 & +1 & 12.91 \\
7 & -1 & +1 & +1 & -1 & 14.63 \\
8 & -1 & +1 & +1 & +1 & 13.97 \\
9 & +1 & -1 & -1 & -1 & 10.32 \\
10 & +1 & -1 & -1 & +1 & 10.27 \\
11 & +1 & -1 & +1 & -1 & 12.39 \\
12 & +1 & -1 & +1 & +1 & 12.21 \\
13 & +1 & +1 & -1 & -1 & 14.59 \\
14 & +1 & +1 & -1 & +1 & 13.96 \\
15 & +1 & +1 & +1 & -1 & 14.86 \\
16 & +1 & +1 & +1 & +1 & 13.11 \\
17 & 0 & 0 & 0 & 0 & 14.09 \\
18 & 0 & 0 & 0 & 0 & 12.87 \\
19 & 0 & 0 & 0 & 0 & 13.17 \\
20 & 0 & 0 & 0 & 0 & 12.69 \\
21 & 0 & 0 & 0 & 0 & 11.43 \\
22 & 0 & 0 & 0 & 0 & 12.56 \\
23 & 0 & 0 & 0 & 0 & 13.29 \\
24 & 0 & 0 & 0 & 0 & 14.02 \\
\hline & & & & &
\end{tabular}

Table 3. Chemical composition of an alloy steel [EN-31] work piece

\begin{tabular}{cccccccc}
\hline $\begin{array}{l}\text { Compo- } \\
\text { sion }\end{array}$ & $\mathrm{C}$ & $\mathrm{Si}$ & $\mathrm{Mn}$ & $\mathrm{Cr}$ & $\mathrm{Co}$ & $\mathrm{S}$ & $\mathrm{P}$ \\
\hline $\mathrm{Wt} \%$ & $0.95-$ & $0.10-$ & $0.30-$ & $1.0-1$ & 0.025 & 0.040 & 0.040 \\
& 1.2 & 0.35 & 0.75 & & & & \\
\hline
\end{tabular}

In this investigation, a commercial alloy steel work piece (EN-31 steel alloy) is machined on heavy duty lathe machine (LTM-20). The chemical composition of the material is shown in Table 3. This material is suitable for a wide variety of automotive type applications the construction of axles, roller bearings, ball bearings, shear blades, spindles, mandrels, forming and molding dies, rollers, blanking and forming tools, knurling tools and spline shafts. These are all examples of automotive components produced using materials where turning is the prominent machining process used. An optical surface roughness measuring microscope was used to measure surface roughness $\left(R_{a}\right)$ of the machined components. The surface roughness was
Table 4. ANOVA for the first-order model (first block)

\begin{tabular}{cccccc}
\hline Source & DF & $\begin{array}{c}\text { Sum of } \\
\text { squares }\end{array}$ & $\begin{array}{c}\text { Mean } \\
\text { squares }\end{array}$ & $\begin{array}{c}\text { F - } \\
\text { value }\end{array}$ & $\begin{array}{c}\text { Prob }> \\
\text { F }\end{array}$ \\
\hline Model & 4 & 17.9219 & 4.4820 & 11.37 & $0.000 \mathrm{~s}$ \\
Error & 7 & 2.7582 & 0.3940 & - & - \\
Total & 11 & 20.6861 & - & - & - \\
\hline
\end{tabular}

Note: $\mathrm{DF}=$ degree of freedom, $\mathrm{s}=$ significant

Table 5. ANOVA for the second-order model (whole block)

\begin{tabular}{cccccc}
\hline Source & DF & $\begin{array}{c}\text { Sum of } \\
\text { squares }\end{array}$ & $\begin{array}{c}\text { Mean } \\
\text { squares }\end{array}$ & $\begin{array}{c}\text { F- } \\
\text { value }\end{array}$ & $\begin{array}{c}\text { Prob }> \\
\text { F }\end{array}$ \\
\hline Model & 11 & 39.8098 & 3.6191 & 9.56 & $0.000 \mathrm{~s}$ \\
Error & 12 & 4.5429 & 0.3786 & - & - \\
Total & 23 & 44.3527 & - & - & - \\
\hline
\end{tabular}

Note: $\mathrm{DF}=$ degree of freedom, $\mathrm{s}=$ significant

measured at three equally spaced locations around the circumference of the workpieces to obtain statistically significant data for each test. The cutting tools used for experimentation were CNMA 120404, CNMA 120408, CNMA 120412 and diamond shape carbide (Make: Widia India Limited, Bangalore). The tool holder used for experimentation was WIDAX SCLCR 1212, Fo9 (ISO Designation).

\section{Results and Discussion}

The experimental study was conducted to see the effect of cutting parameters and tool geometry (i.e., nose radius) on the outcome of the steel turning process. The variation of surface roughness with respect to the variables are shown in Figs. 1 through 5. It can be observed that cutting speed (v) and nose radius (r) have a negative influence, while feed rate (f) and depth of cut (d) have a positive influence on the surface roughness $\left(R_{a}\right)$. The surface roughness $\left(R_{a}\right)$ of EN-31 steel decreased with increased cutting speed (v) and tool nose radius (r) whereas it increased with an increasing feed rate (f) and depth of cut (d). It can also be seen that the feed rate influences the surface roughness more predominantly than the other factors. Large values of tool nose radii also yield low surface roughness as compared to the smaller tool nose radii of the cutting tool (Fig. 5). Hence smaller values of feed rate and depth of cut must be selected in order to achieve better surface finish during the steel turning process. In order to under stand the relationship between the machining response and parameters, the experimental results were used to develop the mathematical models 


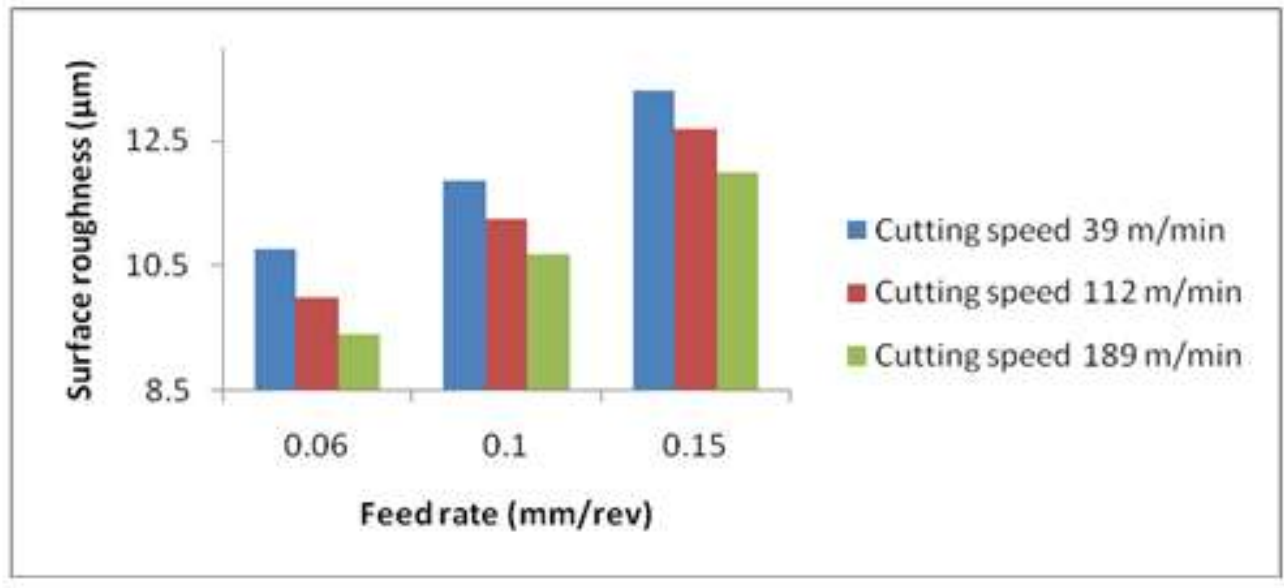

Figure 1. Surface roughness and feed rate relationship (depth of cut $0.2 \mathrm{~mm}$ and nose radius $0.44 \mathrm{~mm}$ )

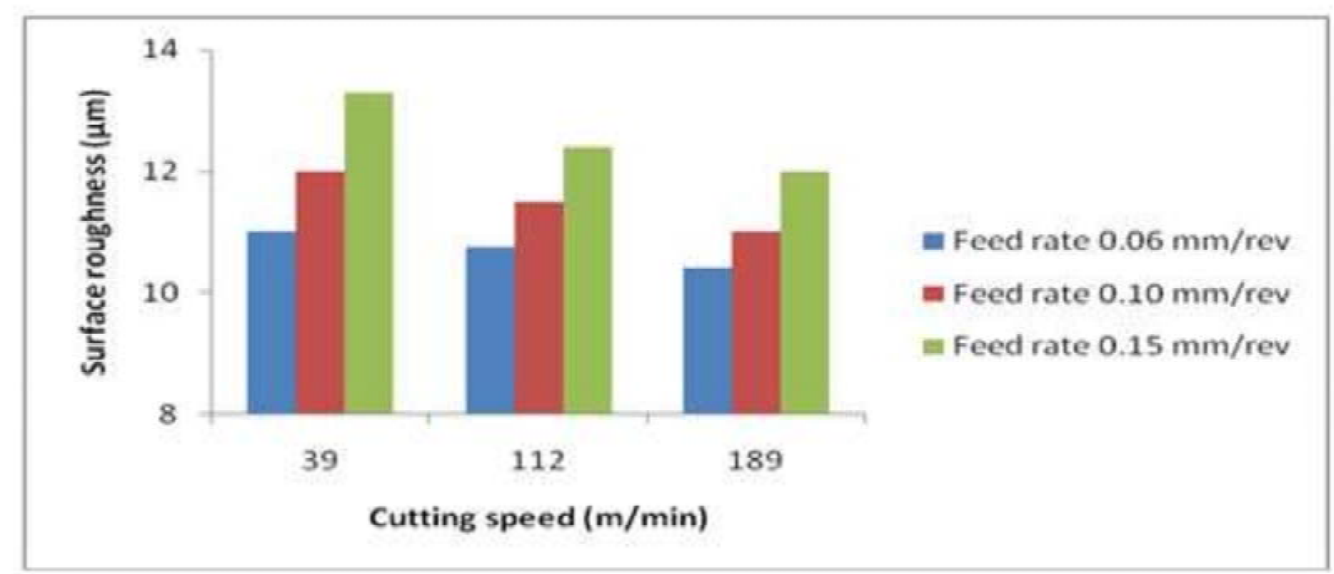

Figure 2. Surface roughness and cutting speed relationship (depth of cut $0.20 \mathrm{~mm}$ and nose radius $0.4 \mathrm{~mm}$ )

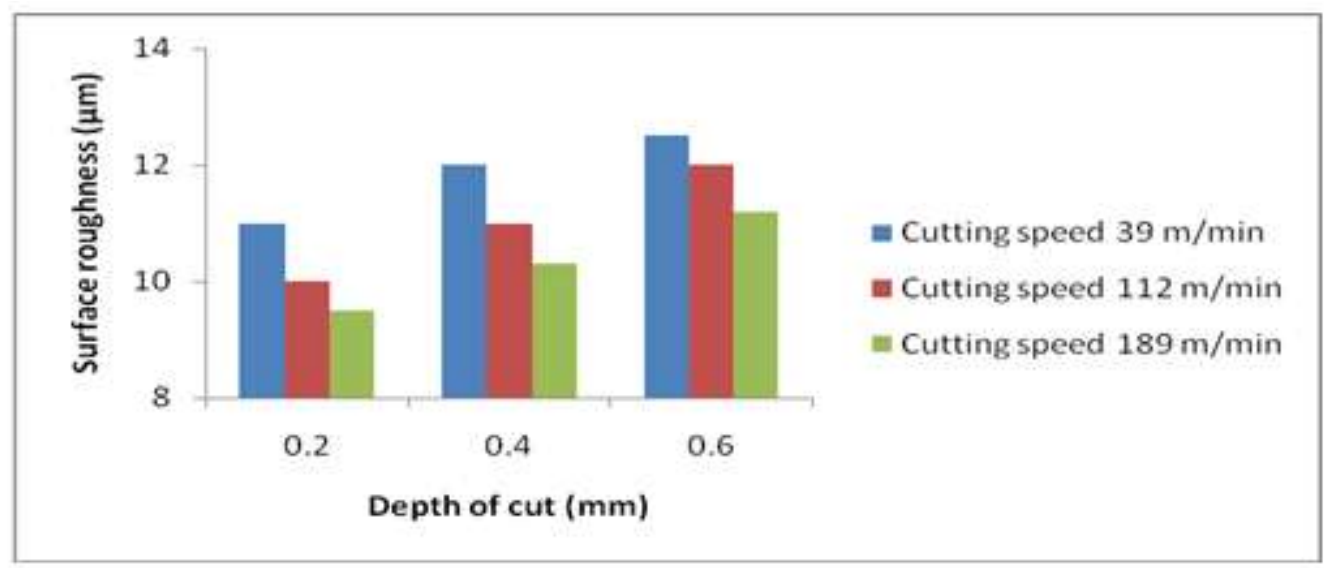

Figure 3. Surface roughness and depth of cut relationship (tool nose radius $0.4 \mathrm{~mm}$ and feed rate $0.6 \mathrm{~mm} / \mathrm{rev}$.)

using RSM. In this work, a commercially available statistical Minitab software package was used for the computation of the regression constants and exponents. The developed equations clearly show that the feed rate is the most influencial parameter on surface roughness followed by tool nose radius and depth of cut. This is in agreement with the work of (Birdie 1993; Sundaram, Lambert 1981). The increase in feed rate increases surface roughness, but surface roughness decreases with increasing cutting velocity and tool nose radius. During machining, if the feed rate is increased, the normal load on the tool also increases 


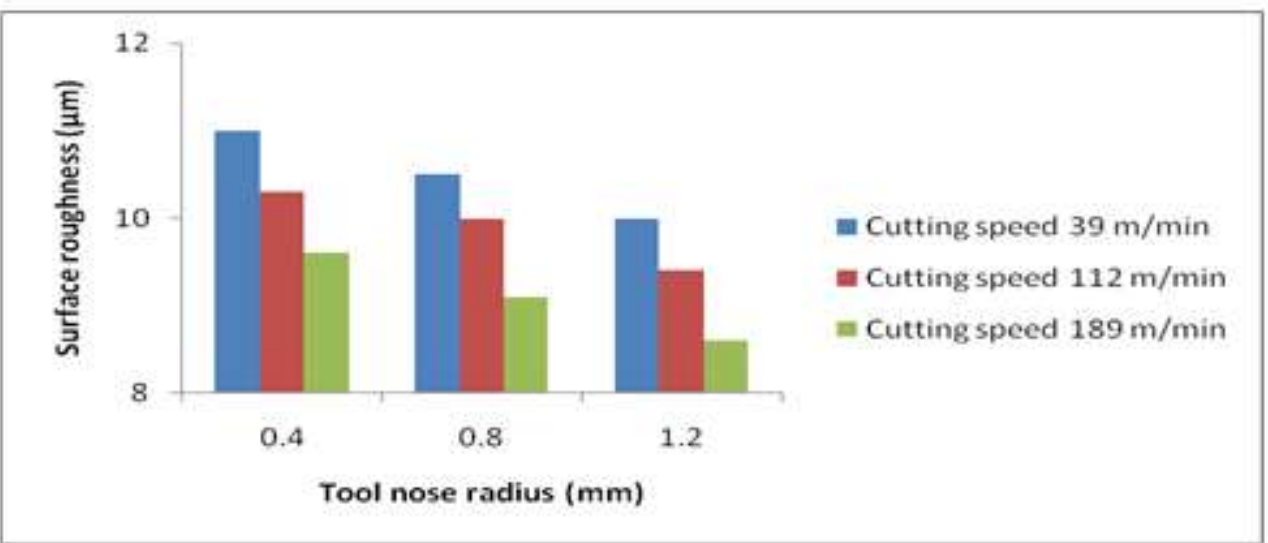

Figure 4. Surface roughness and tool nose radius relationship (depth of cut $0.2 \mathrm{~mm}$ and feed rate $0.06 \mathrm{~mm} / \mathrm{rev}$.)

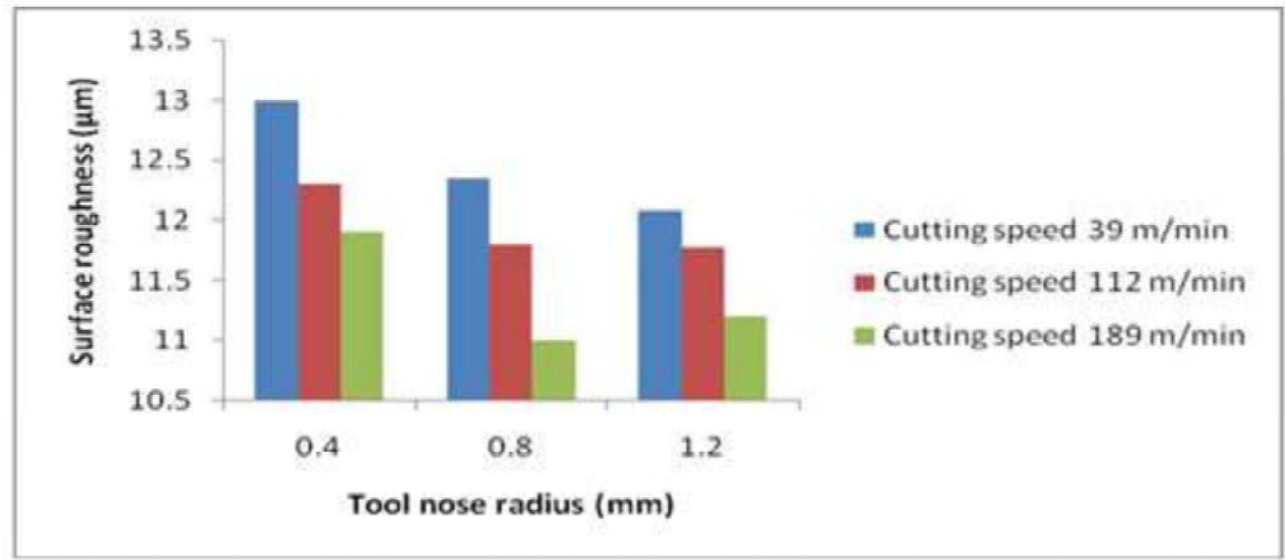

Figure 5. Surface roughness and tool nose radius relationship (depth of cut $0.4 \mathrm{~mm}$ and feed rate $0.1 \mathrm{~mm} / \mathrm{rev}$.)

and it will generate heat which in turn increases the surface roughness. This is anticipated as it is well known that for a given tool nose radius, the theoretical surface roughness is generally $\left(\mathrm{R}_{\mathrm{a}}=\mathrm{f}^{2} / 32 \mathrm{r}\right)$ (Sundaram, Lambert 1981). Thus, with an increase in depth of cut, the surface roughness value increases, because with an increase in depth of cut chatter may result causing degradation of the workpiece surface (Chen 2000), and a larger tool nose radius reduces surface roughness. The surface roughness values obtained by using an insert radius of $1.2 \mathrm{~mm}$ were less than the surface roughness values obtained by using the insert radii of $0.8 \mathrm{~mm}$ and $0.4 \mathrm{~mm}$. The reason for obtaining better surface quality with in insert radius of $1.2 \mathrm{~mm}$ than with the other two inserts may be ascribed to the form of better roundness of this insert than the other two.

\subsection{The Roughness Models}

The proposed first order model developed from the above functional relationship using the RSM method is as follows:

$$
R a=8.6-0.00017 v+28.2 f+3.74 d-0.688 r
$$

The transformed equation of surface roughness prediction is as follows:

$$
R_{a}=26.049\left(v^{-0.0265} f^{0.224} d^{0.114} r^{-0.038}\right)
$$

Equation (11) is derived from the Eq. (10) by substituting the coded values of $x^{1}, x^{2}, x^{3}$ and $x^{4}$ in terms of $\operatorname{lnv}$, lnf, lnd and lnr. The analysis of variance and the F-ratio test have been performed to justify the fitness of the mathematical model. Since the calculated value of the F-ratio is more than the standard tabulated value of the F-ratio for surface roughness as shown in Table 4 , the model is adequate. Their p-values smaller than $5 \%$ or equal to zero, at a $95 \%$ confidence level to represent the definite relationship between the machining parameters and machining response for the turning process. The multiple regression coefficient of the first-order model was found to be 0.8671 . This shows that the first order can explain the variation to the extent of $86.71 \%$. In order to see whether a secondorder model can represent more accurately than the first order, a second order model was developed. It is to be noted from the second-order equations that some of the coefficients are not considered. Only significant 
Table 6. Global optimum solution

\begin{tabular}{ll}
\hline Variable & Value \\
\hline Cutting speed & $189.00 \mathrm{~m} / \mathrm{min}$. \\
Feed rate & $0.06 \mathrm{~mm} / \mathrm{rev}$ \\
depth of cut & $0.20 \mathrm{~mm}$ \\
Tool nose radius & $1.2 \mathrm{~mm}$ \\
Minimum $\mathrm{R}_{\mathrm{a}}$ & $10.26 \mu \mathrm{m}$ \\
\hline
\end{tabular}

Table 7. Confirmation test results

\begin{tabular}{cccccccccc}
\hline $\begin{array}{c}\text { Exp } \\
\text { No }\end{array}$ & $\begin{array}{c}\mathrm{v} \\
(\mathrm{m} / \mathrm{min})\end{array}$ & $\begin{array}{c}\mathrm{f} \\
(\mathrm{mm} / \mathrm{rev})\end{array}$ & $\begin{array}{c}\mathrm{d} \\
(\mathrm{mm})\end{array}$ & $\begin{array}{c}\mathrm{r} \\
(\mathrm{mm})\end{array}$ & $\begin{array}{c}\mathrm{Ra} 1 \\
(\mu \mathrm{m})\end{array}$ & $\begin{array}{c}\text { Ra2 } \\
(\mu \mathrm{m})\end{array}$ & $\begin{array}{c}\text { Ra3 } \\
(\mu \mathrm{m})\end{array}$ & $\begin{array}{c}\text { Exp.Ra } \\
(\mu \mathrm{m})\end{array}$ & $\begin{array}{c}\text { Optimal } \\
\mathrm{Ra}(\mu \mathrm{m})\end{array}$ \\
\hline 1 & 189 & 0.06 & 0.2 & 1.2 & 10.35 & 10.29 & 10.25 & 10.29 & 10.26 \\
\hline
\end{tabular}

Note: $v$ cutting speed $\mathrm{m} / \mathrm{min}$. $\mathrm{f}$ feed rate $\mathrm{mm} / \mathrm{rev}$, $\mathrm{d}$ depth of cut $\mathrm{mm}$ and $\mathrm{r}$ nose radius $\mathrm{mm}$

parameters and their coefficients are included in the second-order equation. The remaining insignificant parameters are omitted. The student's t-test was applied to determine the significance and non-significance of these parameters and their coefficients.

The second-order mathematical model is as follows:

$$
\begin{aligned}
Y_{2} & =5.13+0.0155 v+55.0 f+9.51 d \\
& +0.60 r-0.000051 v^{2}+0.0187 f^{2}-0.0110 d^{2} \\
& -0.00102 r^{2}-48.6 v f-10.5 v d-0.38 d r
\end{aligned}
$$

Where, $\mathrm{Y}_{2}$ is the estimated response of surface roughness based on second-order equation, $\mathrm{v}$ is the cutting speed in meters/minute, $\mathrm{f}$ is the feed rate in $\mathrm{mm} /$ revolution, $\mathrm{d}$ is the depth of cut in $\mathrm{mm}$ and $\mathrm{r}$ is the tool nose radius in $\mathrm{mm}$. It is observed that feed rate has positive influence followed by depth of cut, cutting speed, and tool nose radius on the surface roughness $\left(R_{a}\right)$. The surface roughness $\left(R_{a}\right)$ of En-31 steel decreased with increasing cutting speed (v) and tool nose radius, whereas it increased with an increase in feed rate and depth of cut. The analysis of variance for the second order model is shown in Table 5. The model is adequate since their p-values are smaller than $5 \%$ or equal to zero at a $95 \%$ confidence level to represent the relationship between the machining parameters and machining response for the turning process. The multiple regression coefficient of the second order was found to be 0.8983 . This means that the secondorder can explain the variation to the extent of $89.83 \%$. Since the difference of multiple regression coefficients between the first order and the second order is only $3.12 \%$, it can be concluded that the first order model is adequate to represent the steel turning process under consideration. The first order mathematical model acts as an objective function in order to minimize the output surface roughness factor.

$$
\mathrm{Ra}_{\min }=8.68-0.00017 v+28.2 f+3.74 d-0.688 r
$$

The constrained optimization problem is stated the objective function of minimum $\mathrm{R}_{\mathrm{a}}$ using the above model. The constraints are subjected to, $39<\mathrm{v}<189$, $0.06<\mathrm{f}<0.15,0.2<\mathrm{d}<0.6$ and $0.4<\mathrm{r}<1.2, x i_{1}<x i$ $<x i_{4}$. In this case $x i_{1}$ and $x i_{4}$ are the upper and the lower bounds of process variables $x i$, and $x_{1}, x_{2}, x_{3}$, and $x_{4}$ are the logarithmic transformation of cutting speed, feed rate, depth of cut and tool nose radius. Table 6 shows a global optional solution found at step: 6 with optimum machining conditions. The objective value obtain by LINGO-solver is $10.26223 \mu \mathrm{m}$.

\subsection{Optimization}

The objective of the optimization was to find cutting parameters within the speed range of 39 miters/minute to 189 meters/minute; the feed rate range $0.06 \mathrm{~mm} /$ revolution to $0.15 \mathrm{~mm} /$ revolution, a depth of cut range from $0.2 \mathrm{~mm}$ to $0.6 \mathrm{~mm}$ and a tool nose radius range of 0.4 to $1.2 \mathrm{~mm}$. Cutting parameters all should be carried out so that the surface roughness $\left(\mathrm{R}_{\mathrm{a}}\right)$ is minimized. The best result consisted of speed of 189 meters/minute, a feed rate of 0.06 $\mathrm{mm} /$ revolution, a depth of cut of $0.2 \mathrm{~mm}$ and a tool nose radius of $1.2 \mathrm{~mm}$. This gave an optimum surface roughness $\left(\mathrm{R}_{\mathrm{a}}\right)$ of $10.26 \mu \mathrm{m}$ corresponding to the dezirable $95 \%$ confidence interval. Hence in order to reduce machining time and to achieve a better surface finish and metal removal rate, a combination of a high speed and a low feed rate, with a lower depth of cut and high tool nose radians must be selected for the machining process. This optimization approach is quite advantageous in order to have the range of the surface roughness values and their corresponding optimum machining conditions for certain ranges of input machining parameters. It would be helpful for a manufacturing engineer to select the machining conditions for the desired machining performance of the product. This LINGO-solver approach provides global optimum machining conditions for corresponding minimum values of surface roughness. The LINGO-solver 
approach, used to optimize the mathematical model, was found to be the most useful technique for research. With the known boundaries of surface roughness and machining conditions, machining could be performed with a relatively high rate of success, with selected machining conditions.

\subsection{Verification Test of Optimal Result}

After identifying the most effective parameters, the final step is to verify the optimal values of parameters and the surface roughness (i.e., response) by conducting confirmation experiments and comparing the results of these validation runs with respects to the values obtained by the LINGO-solver optimization model. The validation experiments were conducted according to the optimal process parameter levels (i.e., high cutting speed, low feed rate, low depth of cut and high tool nose radius). Three trials were conducted and the corresponding surface roughness values were measured. The average experimental values and software predicted value are $10.29 \mu \mathrm{m}$ and 10.26 respectively, at the $95 \%$ confidence levels. The Table. 7 shows experimental values and optimal values of surface roughness. The experimental values were compared with the predicted values from the LINGOsolver and the software found that the experimental values were very close to the predicted values.

\section{Conclusions}

A reliable surface roughness model for steel turning was developed using RSM and incorporated cutting speed, feed rate, depth of cut, and the tool nose radius. The study was optimized by the LINGO-solver approach, which is a global optimization technique. This has resulted in a fairly useful method of obtaining process parameters in order to attain the required surface quality. The optimal parameter combination of the turning process corresponded to a cutting speed of 189 mitres/minute, a feed rate of $0.06 \mathrm{~mm} /$ revolution, a depth of cut of $0.2 \mathrm{~mm}$, and a tool nose radius of 1.2 $\mathrm{mm}$ by the Lingo-solver approach. This has validated the trends available in the literature and extended the data range to the present operating conditions, apart from improving the accuracy and modeling by involving the most recent modeling method. The application of LINGO-solver optimization to obtain optimal machining conditions will be quite useful at the computational planning stage in the production of high quality goods with tight tolerances by a variety of machining operations, and in the adaptive control of automated machine tools.

\section{Acknowledgment}

The authors would like to express their deep grati- tude to the Department of Mechanical Engineering of Aligarh Muslim University for providing laboratory facilities and financial support.

\section{References}

Abhang LB, Hameedullah M (2010), Analysis of surface roughness by turning process using statistical method. Proceedings of the Int. Conf. on Advances in Industrial Engineering Application Chennai, India 138-146.

Abhang LB, Hameedullah M (2010), A predictive model for tool wear rate in metal cutting using response surface methodology. Proceedings of the Int. Conf. on Advances in Industrial Engineering Applications Chennai, India 171-180.

Aslan E, Camuscu N, Birgoren B (2007), Design optimization of cutting parameters when turning hardened AISI4140 steel with AL2O3 + TiCN mixed ceramic tool. Materials and Design 28:1618-1622.

Birdie MA (1993), Surface roughness model for turning grey C.I. (154BHN). Proceedings of Institution of Mechanical Engineering, Part B, J. of Engineering Manufacture 207:43-54.

Chen W (2000), Cutting forces and surface finish when machining medium hardness steel using CBN tools. Int. J. of Machine Tools and Manufacture 4(1):455-466.

Dilbag R (2007), Optimization of tool geometry and cutting parameters for hard turning. J. of Materials and Manufacturing Process 22:15-21

Feng CX, Wang X (2002), Development of empirical models for surface roughness prediction in finish turning. The Int. J. of Advanced Manufacturing Technology 20:348-356.

Hasegawa MA, Seireg RA, Lindberg (1976), Surface roughness model for turning. Int. J. of Tribology $8(2): 285-289$.

Konig W, Komanduri R, Tonshoff HK, Ackerson HG (1984), Machining of hard materials. Annals of CIRP 33(2):417-427.

Kopac J, Bahor M, Sokovice M (2002), Optimal machining parameters for achieving the desired surface roughness in fine turning of cold preformed steel work piece. Int. J. of Machine tools and Manufacture 42:707-716.

Manna A, Bhattacharyya B (2004), Investigation for optimal parametric combination for achieving better surface finish during turning of $\mathrm{Al} / \mathrm{Sic}-\mathrm{MMC}$. Int. J. of Advanced Manufacturing Technology 23:658-665.

Montgomery DC (1991), Design and analysis of experiment's. Third edition, John Wiley and Sons, New York, USA 521-568.

Mehrban D, Naderi V, Panahizadeh H, Moslemi N 
(2008), Modeling of tool life in turning process using experimental method. Int. J. of Material Forming Springer/ESA Form 1-4.

Nalbant M, Gokkaya H, Sur G (2007), Application of taguchi method in the optimization of cutting parameters for surface roughness in turning. Materials and Design 28:1379-1385.

Ozel T, Karpat Y (2005), Predictive modeling of surface roughness and tool wear in hard turning using regression and neural networks. Int. J. of Machine Tools and Manufacture 45:467-479.

Suresh R, Deshmukh S (2002), A genetic algorithmic approach for optimization of surface roughness prediction model. Int. J. of machine-tools and manufactures 42:675-680.

Sundaram RM, Lambert BK (1981), Mathematical models to predict surface finish in fine turning of steel. Part 1, Int. J. of Production Research 19:547-556.

Wang X, Balaji AK, Jawahir IS (2002), Performance based optimal selection of cutting condition and cutting tools in multi-pass turning operations using genetic algorithms. Int. J. of Production Research 40(9):2050-2065.

Yang WH, Tarng YS (1998), Design optimization of cutting parameters for turning operations based on the Taguchi method. J. of Materials Processing Technology 84:122-129. 